\title{
O complexo agroindustrial da cana-de-açúcar no Brasil: uma discussão sobre aspectos atuais relacionados ao etanol biocombustível
}

\author{
Márcia França Ribeiro F. dos Santos* \\ Suzana Borschiver* \\ Maria Antonieta P. Gimenes Couto**
}

\begin{abstract}
RESUMO - O Brasil apresenta uma série de vantagens comparativas e competitivas, como condições climáticas favoráveis e vasto conhecimento adquirido com relação a agricultura tropical, que o levam a uma posição de destaque em escala mundial com relação à produção de energia. No entanto, para que o mercado de bioenergia no Brasil, em especial no tocante a indústria sucroalcooleira, se desenvolva de maneira sustentável é necessário que se proceda com uma análise dos impactos desta indústria do ponto de vista ambiental, econômica e social. Assim, o presente artigo visa propor uma discussão sobre aspectos relevantes do complexo agroindustrial da cana-de-açúcar no Brasil, com ênfase na produção do bioetanol, de modo a fomentar políticas públicas nacionais de modo a consolidar a posição do país no mercado mundial de biocombustíveis.
\end{abstract}

Palavras-chave: Etanol. Biocombustível. Brasil. Energia.

\section{INTRODUÇÃO}

O setor sucroalcooleiro desempenha um papel de destaque no agronegócio brasileiro, que por sua vez tem um impacto forte na Balança Comercial do Brasil. De acordo com dados da Secretaria de Comércio Exterior, em 2010 as vendas de cinco commodities - minério de ferro, petróleo bruto, soja (grão, farelo e óleo), açúcar (bruto e refinado) e complexo de carnes - responderam por $43,4 \%$ do valor total exportado pelo Brasil, uma fatia bastante superior aos $27 \%$ de 2004 (MINISTÉRIO DO PLANEJAMENTO, 2011).

Neste setor, o país é líder mundial na produção de cana-de-açúcar, etanol e açúcar com 572,7 milhões de toneladas, 27,7 bilhões de litros e 31,3 milhões de toneladas, respectivamente, na safra de 2008/2009 (CORTEZ, 2010).

Em média, $50 \%$ da cana colhida é destinada a produção de álcool e os demais 50\% são destinados a produção de açúcar. Cerca de $2 / 3$ do açúcar produzido é destinado ao merca-

\footnotetext{
* Doutoranda em Tecnologia dos Processos Químicos e Bioquímicos da Escola de Química na UFRJ. Analista de Gestão, Planejamento do IBGE. Endereço eletrônico: marciafribeiro@yahoo.com.br.

** Doutora em Tecnologia dos Processos Químicos e Bioquímicos na UFRJ. Professora adjunta da Escola de Química da UFRJ. Endereço eletrônico: suzana@eq.com.br.

*** Doutora em Tecnologia dos Processos Químicos e Bioquímicos na UFRJ. Professora adjunta da Escola de Química da UFRJ. Endereço eletrônico: gimenes@eq.com.br.
} 
do externo enquanto que o restante atende ao mercado interno. Quanto a produção de álcool, cerca de $85 \%$ é direcionado ao mercado interno, sendo que destes $90 \%$ é destinado ao seu uso como carburante, e o restante atende ao mercado externo (BASTOS, 2007).

Assim, é possível notar que o principal uso do etanol é como combustível líquido, misturado à gasolina ou usado como insumo na fabricação de aditivo à gasolina - o etil tercbutil éter (ETBE), derivado do petróleo, que tem sido proibido pelo risco de contaminação de águas subterrâneas. O uso como combustível (na proporção de $20 \%$ a 100\%) é praticamente exclusivo do Brasil e dos Estados Unidos, enquanto o uso como aditivo ( $2 \%$ a $10 \%$ ) ocorre nos Estados Unidos (EUA), União Européia (UE), Índia e China, entre outros países (USDA, 2006 apud BASTOS, 2007).

O etanol pode ser produzido nas seguintes formas, sendo os dois primeiros com aplicação carburante: (i) hidratado - aquele que possui 96\% de álcool puro e 4\% de água e é utilizado em motores a álcool e flexíveis; (ii) anidro - usado como aditivo em combustíveis com gasolina, sendo composto por 99,5\% de álcool puro e 0,5\% de água; e (iii) industrial - demais usos não carburantes.

Como o mercado de etanol já se encontra consolidado no Brasil, agora a cana-de-açúcar tem sido vista cada vez mais como uma fonte de energia, e não somente uma fonte de alimento. Considerando o cenário mundial de esgotamento das reservas de fontes não renováveis como petróleo, os países em desenvolvimento têm buscado novas alternativas ao petróleo.

O Brasil se encontra em uma posição de vantagem, principalmente quando se fala de etanol da cana-de-açúcar. No entanto, é necessário que nosso país consolide sua posição no mercado mundial de energia de forma sustentável, ou seja, considerando questões de natureza ambiental, econômica e social. Assim, o presente artigo visa apresentar e analisar questões atuais e polêmicas que envolvem o complexo sucroalcooleiro, com ênfase na produção do bioetanol, no intuito de subsidiar a formulação de políticas públicas nacionais de modo que se potencialize a atuação brasileira como uma potência energética.

\section{ASPECTOS RELEVANTES SOBRE A CADEIA SUCROALCOOLEIRA NO BRA-} SIL

\subsection{PRODUÇÃO DE ALIMENTOS X PRODUÇÃO DE BIOCOMBUSTÍVEIS}

O cenário de expansão mundial dos biocombustíveis tem ampliado o debate sobre a questão de segurança alimentar, em especial a polêmica entre comida versus biocombustível; para alguns críticos os biocombustíveis estão passando de alternativa de energia ecologicamente 
correta para potenciais fontes de distúrbios no sistema agrícola mundial causando o inflacionamento dos preços dos alimentos (SEIBEL, 2007).

Segundo o relatório sobre o impacto dos biocombustíveis, elaborado pela Organização para a Cooperação e Desenvolvimento Econômico (OCDE), os mesmos podem promover uma cura pior do que a doença que tentam tratar porque podem acabar sendo prejudiciais ao meio ambiente e encarecendo os alimentos (ABIODIESEL, 2007).

A OCDE tem orientado os governos para que promovam o corte aos subsídios para este setor e que incentivem a realização de pesquisas com vistas a encontrar novas tecnologias que evitem a concorrência pela terra usada para a produção de alimentos, especialmente em países da UE e EUA, que muitas vezes têm promovido incentivos fiscais com o intuito de proteger a agricultura da abertura comercial.

Para explicar a alta do preço de alimentos no mundo, o argumento mais comum é jogar a culpa na produção de biocombustíveis; ou seja, a oferta de comida teria diminuído em decorrência da redução de áreas agriculturáveis para o setor, levando a uma inflação nas gôndolas dos supermercados.

Em relação ao futuro da oferta de alimentos frente ao cultivo de culturas destinadas a produção de biocombustíveis, (SEIBEL, 2007, p. 105) cita que "em boa parte, as preocupações a respeito dos efeitos colaterais da expansão do etanol têm sido baseadas no comportamento dos preços mundiais de alguns grupos de alimentos nos últimos meses”.

Como efeitos colaterais podem ser citados: (1) o aumento da cotação da commodity milho nas bolsas americanas afetando a extensa cadeia de empresas que utilizam a matériaprima na formulação de seus produtos considerando que os americanos estão transformando em etanol grande parte do milho produzido em seu território, aumentando sua escassez para a exportação; e (2) o aumento das queimadas que estão promovendo a destruição em largas porções de florestas nativas na Ásia, em especial na Malásia e Indonésia, ocorrendo a substituição da mata por plantações de palmeiras para a produção do biodiesel (SEIBEL, 2007).

Para se ter uma dimensão desta polêmica, a Tabela 1 mostra a comparação entre a produção de alimentos e álcool para Brasil e EUA a partir da cana-de-açúcar e do milho respectivamente.

As projeções apontam que, tanto para os EUA como para o Brasil, a quantidade de alimento está diminuindo enquanto a produção de álcool está aumentando. No entanto, o modelo adotado nos EUA não tem se mostrado sustentável e apresenta desvantagens quando comparado ao Brasil, pelas seguintes razões: (1) a disputa por espaço no campo entre culturas destinadas à comida e energia é uma realidade nos EUA, considerando que 
o terreno para a expansão agrícola americana é mais restrito do que no Brasil; (2) o etanol produzido a partir da cana-de-açúcar leva vantagem quando comparado ao do milho porque é cerca de $25 \%$ mais barato, sua produtividade de litros por hectare é o dobro da americana e gasta quatro vezes menos energia do que o etanol produzido a partir do milho.

TABELA 1 - COMPARAÇÃO ENTRE A PRODUÇÃO DE ALIMENTOS E ÁLCOOL PARA BRASIL E EUA A PARTIR DE CANA-DE-AÇÚCAR E MILHO, RESPECTIVAMENTE

\begin{tabular}{l|rrrrrr}
\hline \multicolumn{1}{c|}{ Comparação } & \multicolumn{2}{c|}{ Brasil (cana-de-açúcar) } & \multicolumn{3}{c}{ EUA (milho) } \\
\hline Ano & 2005 & 2010 & 2014 & 2005 & 2010 & 2014 \\
Total destinado a produção de & 53 & 41 & 33 & 86 & 71 & 64 \\
alimentos em (\%) & 47 & 59 & 67 & 14 & 29 & 36 \\
Total destinado à produção de & & & & &
\end{tabular}

FONTE: SEIBEL, 2007.

NOTA: Projeções para 2010 e 2014 de acordo com os dados USDA, Única e Agroconsult.

Um estudo feito na Faculdade de Agronomia e Medicina Veterinária da Universidade de Brasília (UNB) mostra que no Brasil os dois setores convivem perfeitamente, sem que um afete a produção do outro (SECOM, 2008).

Para que houvesse prejuízo à disponibilidade de alimentos no Brasil, as estatísticas deveriam apontar queda nas safras. Mas o que vem acontecendo é exatamente o contrário segundo a pesquisa realizada. A produtividade das culturas de milho, arroz e feijão cresceu entre os anos de 1995 e 2006. E o mais surpreendente: a produção agroalimentar tem aumentado sem precisar de novas terras. As culturas alimentares, sem necessidade de ocupar novas áreas, deixaram disponíveis espaços para o avanço do plantio de matéria-prima para os biocombustíveis, como soja e cana-de-açúcar, não cabendo assim, falar entre concorrência entre as culturas alimentares e aquela destinada a produção de biocombustíveis.

Cabe destacar que os ganhos de produtividade quanto a produção de grãos crescem ao ritmo de 5,4\% em média por ano desde 1991. Segundo os estudos de Strapasson (CASTRO, 2008) a produção destas commodities pode dobrar nos próximos dez anos utilizando-se praticamente a mesma área plantada em 2008, estimada pela Conab entre 47,9 milhões e 18,6 milhões de hectares. No período de 1991 a 2008, enquanto a área cultivada com grãos no país evoluiu $1,3 \%$ ao ano, a produção deu saltos de 8,5\% anuais, até atingir, conforme previsão, 142,1 milhões de toneladas em 2008.

Atualmente o Brasil é o país com maior potencial de terras disponíveis para conciliar as duas fortes demandas do mundo - a produção de alimentos e de biocombustíveis. Segundo o autor no país há espaço para o crescimento de todas as culturas pois reúne quatro condições indispensáveis para a expansão agrícola: terra, água, clima e tecnologia (CASTRO, 2008).

A cana pode avançar ainda sobre áreas de pastagem consideradas degradadas, o que 
significa não comprometer os espaços destinados com as culturas de grãos. Conforme os dados do Ministério da Agricultura, Pecuária e Abastecimento (MAPA, 2010), o Brasil tem 65 milhões de hectares em terra apta e disponível para a expansão da cultura da cana - dos quais 37 milhões são áreas de pastagem, valor este inferior aos cerca de 330 milhões de hectares. Assim, fica evidenciado a não existência da competição de biocombustíveis e alimentos.

\subsection{DESMATAMENTO DA FLORESTA AMAZÔNICA E A FRONTEIRA AGRÍCOLA}

A questão do desmatamento no Brasil diz respeito ao temor internacional de que o crescimento da cana afete, direta ou indiretamente, as florestas nacionais. De acordo com especialistas americanos destruir ecossistemas naturais, como a Floresta Amazônica brasileira, para dar lugar a cultivos destinados à produção de biocombustíveis agrava o aquecimento global, gerando, por muitas décadas, mais dióxido de carbono $\left(\mathrm{CO}_{2}\right)$, o principal gás causador do efeito estufa (EMBAR, 2008).

Conforme os dados divulgados pelo Instituto Nacional de Pesquisas Espaciais (INPE) de agosto de 2008 a julho de 2009, foram desmatados cerca de $7.000 \mathrm{~km}^{2}$ da Floresta Amazônica brasileira (INPE, 2009). Este número, que representa um aumento vertiginoso no ritmo do desflorestamento, foi atribuído pelas autoridades brasileiras, entre outros motivos, à disparada no cultivo da soja em algumas regiões.

Cientistas americanos explicaram que o forte aumento da demanda de etanol de milho nos Estados Unidos provoca a destruição crescente da Floresta Amazônica no Brasil, uma vez que para responder à demanda do etanol, os agricultores dos EUA pararam de alternar os cultivos de milho com as de soja. Desta forma, os brasileiros precisam produzir ainda mais soja para atender à demanda mundial insatisfeita, e isso acaba por afetar as florestas virgens. Afirmam ainda que todos os biocombustíveis que se utilizam atualmente promovem uma destruição da natureza de forma direta ou indireta.

$\mathrm{O}$ volume de $\mathrm{CO}_{2}$ encontrado na atmosfera oriundo da derrubada de florestas virgens, savanas, turfeiras ou estepes ultrapassa o volume de $\mathrm{CO}_{2}$ que não é emitido graças à utilização de biocombustíveis. Sendo assim, o desmatamento seria ainda menos favorável ao meio ambiente do que a não utilização dos biocombustíveis.

Os desmatamentos para o cultivo do milho ou da cana-de-açúcar, a partir dos quais se produz etanol ou ainda da soja para biodiesel, são responsáveis por volumes de emissões de $\mathrm{CO}_{2}$ de 17 a 420 vezes maiores que a redução anual resultante da substituição de combustíveis fósseis por biocombustíveis, calcularam pesquisadores. Além disso, o carbono retido nas árvores e plantas derrubadas assim como o solo onde estavam estes vegetais é lançado à atmosfera 
em forma de $\mathrm{CO}_{2}$ em um processo pode demorar muitas décadas, talvez séculos (EMBAR, 2008).

Além disso, segundo Veiga Filho (2008) esta discussão é rebatida objetivamente conforme os dados que mostram que a expansão da cana não avança sobre as áreas de florestas, mas sobre as áreas de pastagens e agrícolas. Desta forma, o Brasil possui áreas para explorar novas atividades agrícolas, sem a necessidade de cortar uma única árvore.

A fronteira agrícola brasileira está localizada em regiões pouco exploradas ou utilizadas de forma extensiva, principalmente em pastagens, não se concentrando na Floresta Amazônica nem de forma direta muito menos indireta. Trata-se de ganhos de produtividade, e não de mero deslocamentos de atividades.

\subsection{COMPARAÇÃO COM OUTRAS CULTURAS PARA PRODUÇÃO DE ÁLCOOL}

Os principais produtos obtidos a partir da cana-de-açúcar são o açúcar e o etanol. No entanto, o chamado bioetanol pode ser produzido com base em qualquer biomassa que contenha quantidades significativas de amido ou açúcares. Atualmente, há um leve predomínio da produção com base em materiais amiláceos (53\% do total), como milho, trigo e outros cereais e grãos (BNDES, 2008).

A Tabela 2 mostra as rotas implementadas comercialmente; existem ainda as rotas alternativas que estão sendo desenvolvidas como a hidrólise de materiais celulósicos. Cabe destacar que o bioetanol da cana apresenta vantagens em todos os parâmetros quando comparado com o bioetanol produzido a partir do trigo ou do milho.

TABELA 2 - QUADRO DE BIOCOMBUSTÍVEIS

\begin{tabular}{|c|c|c|c|c|c|}
\hline Biocombustível & Matéria-prima & $\begin{array}{c}\text { Redução na } \\
\text { emissão de } \\
\text { gases do efeito } \\
\text { estufa }\end{array}$ & Custo de produção & $\begin{array}{c}\text { Produção de } \\
\text { biocombustível } \\
\text { por hectare }\end{array}$ & Terras utilizadas \\
\hline Bioetanol & $\begin{array}{r}\text { Grãos (trigo, } \\
\text { milho) }\end{array}$ & $\begin{array}{r}\text { Moderado a } \\
\text { baixo }\end{array}$ & Moderado & Moderado & Terras férteis \\
\hline Bioetanol & Cana-de-açúcar & Alto & Baixo & Alto & Terras férteis \\
\hline Biodiesel & $\begin{array}{r}\text { Óleos de se- } \\
\text { mente }\end{array}$ & Moderado & Moderado & Baixo & Terras férteis \\
\hline Biodiesel & Óleo de palma & Moderado & $\begin{array}{r}\text { Moderado a } \\
\text { baixo }\end{array}$ & Moderado & $\begin{array}{r}\text { Terras litorâneas } \\
\text { e úmidas }\end{array}$ \\
\hline
\end{tabular}

FONTE: BNDES, 2008.

Uma comparação entre as diferentes rotas para a produção de bioetanol é apresentada no Gráfico 1, que evidencia como podem ser diferentes os índices de produtividade por unidade de área cultivada. Os resultados do gráfico correspondem a lavouras em condições de boa produtividade, que em alguns casos podem implicar elevado uso de insumos, tendo sido 
tomados da literatura (GPC, 2008 apud BNDES 2008) modificados para o caso da cana e do sorgo, em função das análises apresentadas adiante neste trabalho.

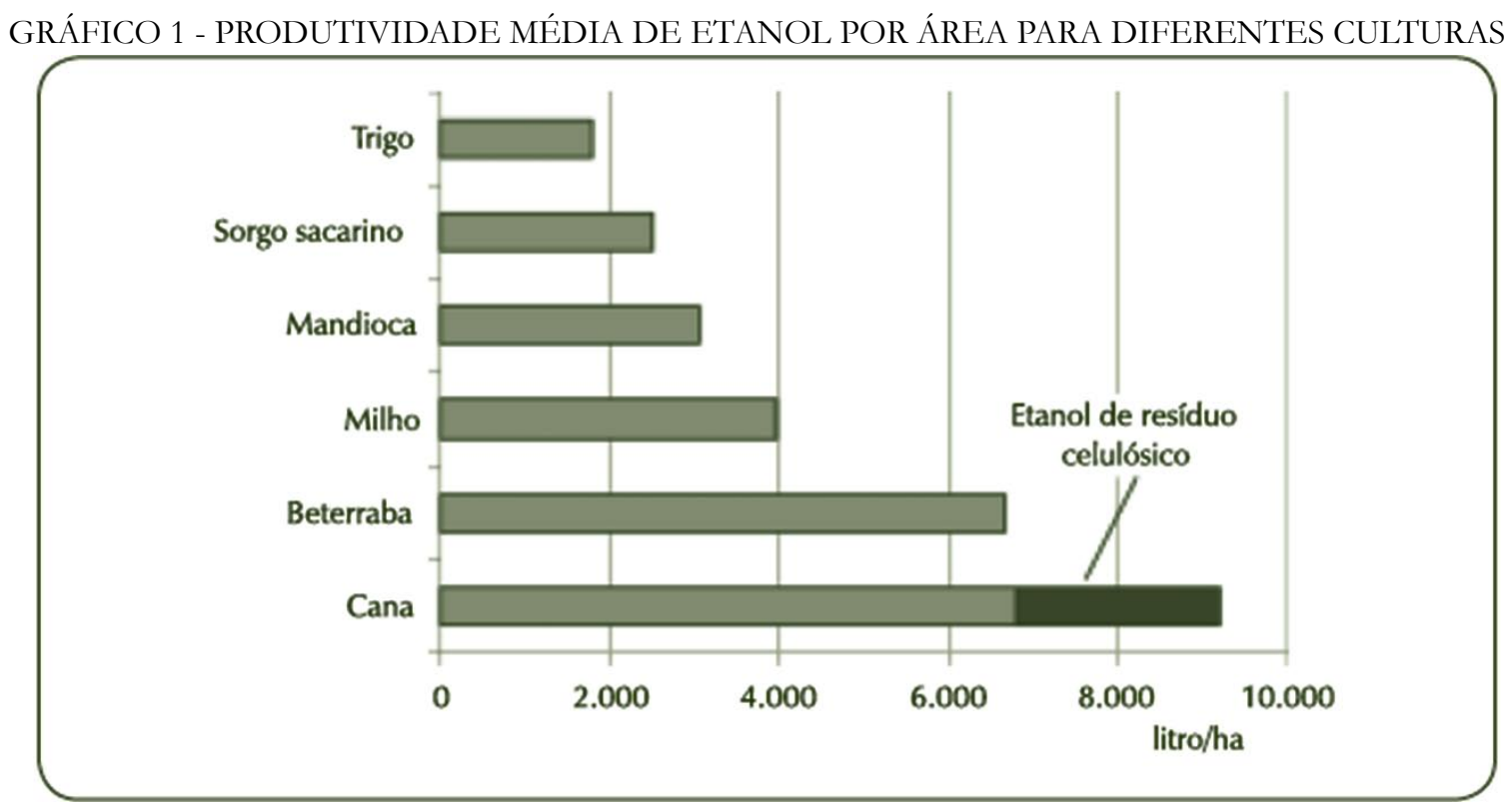

FONTE: BNDES (2008).

As tecnologias industriais implícitas no Gráfico 1, para conversão de açúcares e amido em bioetanol, podem ser consideradas maduras e disponíveis, exceto as referentes à hidrólise de materiais lignocelulósicos, ora em desenvolvimento, adotadas para a obtenção de bioetanol da parte celulósica da cana. Para a cana, consideraram-se uma produção de 80 toneladas de cana por hectare, uma produtividade de 85 litros de bioetanol por tonelada de cana processada e a utilização de 30\% do bagaço disponível e metade da palha, convertida em bioetanol à razão de 400 litros por tonelada de biomassa celulósica seca.

\subsubsection{Custo de produção do etanol}

Nos Estados Unidos, os custos variáveis do etanol do milho estão em US $\$$ 0,96/galão e os custos fixos entre US\$1,05 e US\$3,00, enquanto o Brasil tem custos variáveis de US\$ 0,89 /galão e custos fixos de US\$ $0,21 /$ galão, com custos totais de US $\$ 1,10 /$ galão (MARTINES-FILHO et al., 2006). Segundo a Unica (2009), os custos de produção do etanol no Brasil estariam em US\$ 0,90 - US\$1,30/galão.

Os números do United State Department of Agriculture (USDA) comparam o custo de produção do etanol fabricado com base em diferentes matérias-primas conforme ilustrado no Gráfico 2, que evidencia a vantagem comparativa de custos do etanol brasileiro. Segundo especialistas, mesmo com a hipótese improvável de o preço do petróleo retornar a seus patamares 
históricos (US\$30-35/barril), o etanol brasileiro não perderia sua competitividade.

GRÁFICO 2 - CUSTO DE PRODUÇÃO DO ETANOL (US\$/GALÃO)

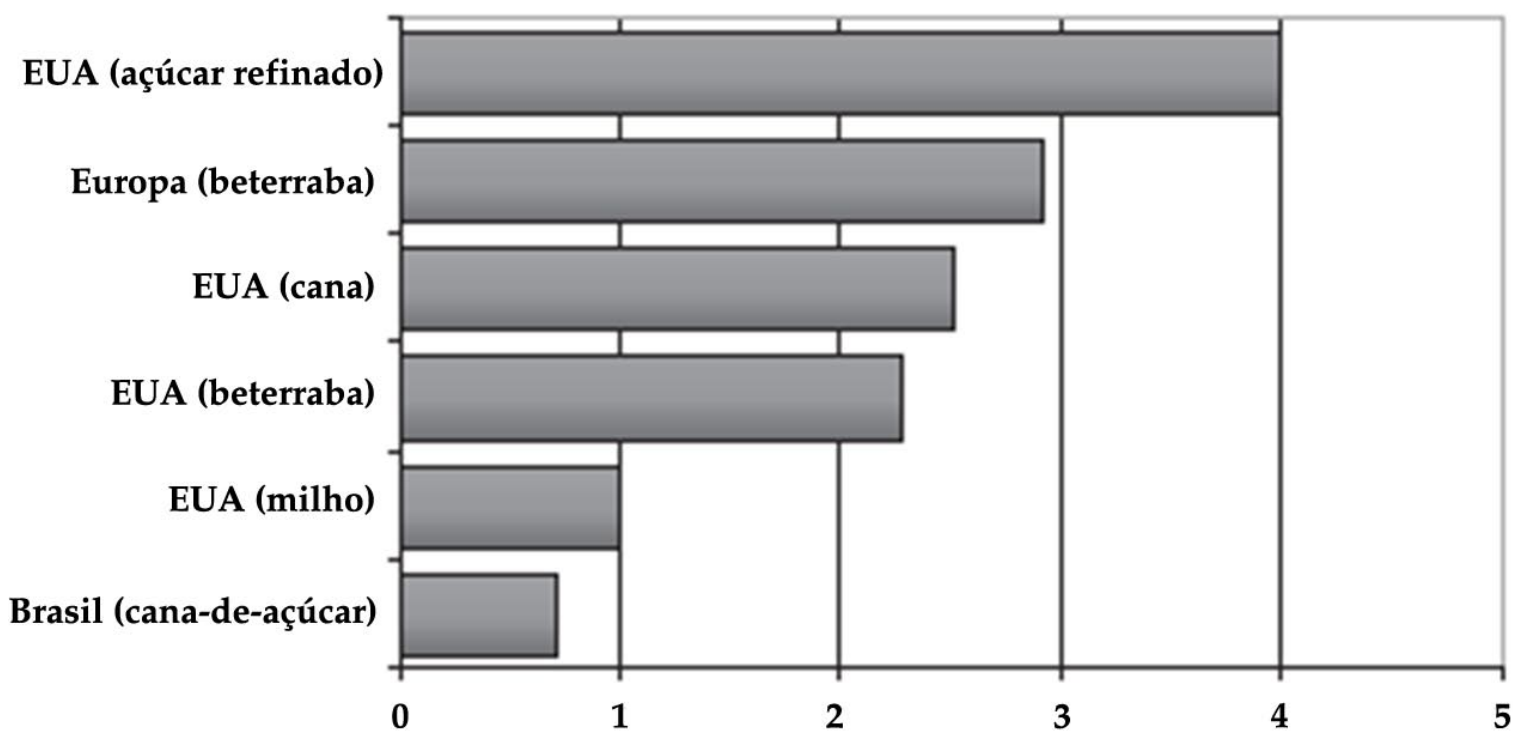

FONTE: USDA (2009 apud BASTOS, 2007).

\subsection{IMPACTOS ENERGÉTICOS E AMBIENTAIS DO ETANOL}

Diversos estudos já foram realizados com o intuito de avaliar os impactos energéticos e ambientais dos biocombustíveis. No caso da cana, considerando a substituição de gasolina e a mitigação das emissões do efeito estufa, já são reconhecidas há bastante tempo as vantagens ambientais do bioetanol no Brasil, desde a divulgação dos primeiros trabalhos mais detalhados sobre o tema (MACEDO \& HORTA NOGUEIRA, 1985; MACEDO 1992 apud BNDES, 2008).

Desde então, estudos de atualização vêm sendo publicados, acompanhando a evolução das práticas agroindustriais no setor sucroalcooleiro e o avanço do conhecimento sobre os aspectos ambientais.

\subsubsection{Balanço energético favorável}

$\mathrm{Na}$ última avaliação publicada, foram analisados os balanços de energia e emissões de Gases do Efeito Estufa (GEE) para a situação atual e um cenário para 2020, considerando uma abordagem "do plantio da cana ao portão da usina" (MACEDO et al., 2008). Com base nas médias dos principais parâmetros agrícolas e industriais de 44 usinas na Região Centro-Sul do Brasil, esse estudo indica que, atualmente, para cada unidade de energia fóssil utilizada na produção do bioetanol de cana, mais de nove unidades de energia renovável são produzidas, na 
forma de bioetanol e excedentes de energia elétrica e bagaço, como apresentado na Tabela 3.

TABELA 3 - BALANÇO DE ENERGIA NA PRODUÇÃO DE BIOETANOL DE CANA (MJ/TC)

\begin{tabular}{l|r|r}
\hline Componente do balanço energético & $\mathbf{2 0 0 5 / 2 0 0 6}$ & Cenário 2020 \\
\hline Produção e transporte de cana & 210,2 & 238,0 \\
Produção de bioetanol & 23,6 & 24,0 \\
Input fóssil (total) & 233,8 & 262,0 \\
Bioetanol & $1.926,0$ & $2.060,0$ \\
Excedente de bagaço & 176,0 & 0,0 \\
Excedente de eletricidade & 82,8 & 972,0 \\
Outup renovável (total) & $2.185,0$ & $3.032,0$ \\
\hline \multicolumn{1}{c}{ Produção/consumo energético } & & 7,9 \\
\hline Bioetanol + bagaço & 9,0 & 11,6 \\
Bioetanol + bagaço + eletricidade & 9,3 & \\
\hline
\end{tabular}

FONTE: Macedo et al., (2008).

É interessante notar que, mesmo considerando a maior mecanização e o uso de tecnologias agrícolas que devem ampliar a demanda energética em 12\% nesse período de 15 anos, o incremento da produção de bioetanol por tonelada de cana processada e, principalmente, a significativa ampliação da produção de energia elétrica deverão permitir que a agroindústria da cana-de-açúcar se mantenha como a mais eficiente forma de produzir biocombustíveis e, em proporções crescentes, bioeletricidade, com expectativas de que a relação de energia (produção/consumo energético) alcance níveis superiores a 11.

Em termos de emissões de GEE, atualmente a produção do bioetanol anidro de canade-açúcar envolve uma emissão de quase $440 \mathrm{~kg} \mathrm{CO} 2 \mathrm{eq} / \mathrm{m}^{3}$ de bioetanol.

Contudo, quando considerado o seu uso em misturas com gasolina, em teores de $25 \%$, como adotado no Brasil, associado aos efeitos devido ao uso do bagaço e da eletricidade excedentes, a emissão líquida evitada, resultante da diferença entre as emissões na produção e as emissões evitadas, alcança $1.900 \mathrm{~kg} \mathrm{CO}_{2} \mathrm{eq} / \mathrm{m}^{3}$ de bioetanol, para as condições atuais, e possivelmente chegará a níveis superiores a $2.260 \mathrm{~kg} \mathrm{CO}$ eq $/ \mathrm{m}^{3}$ de bioetanol, para as condições esperadas para 2020. Isso ocorre porque, quando se substitui a gasolina pelo bioetanol, toda a emissão associada ao uso do combustível fóssil é mitigada, passando a valer somente as emissões relacionadas com a produção do bioetanol, que, por sua vez, dependem da eficiência no uso final desse biocombustível.

Para essas avaliações, foi assumido ainda que o bagaço excedente deve substituir óleo combustível em caldeiras e que a energia elétrica produzida na agroindústria do bioetanol passa a ocupar o lugar de energia elétrica gerada com os fatores de emissão médios mundiais (579 e $560 \mathrm{t} \mathrm{CO}_{2}$ eq/GWh para 2005 e 2020, respectivamente) (MACEDO et al., 2008).

Segundo os estudos do professor Weber Amaral (VEIGA FILHO, 2008) o etanol da 
cana possui capacidade para produzir 9,2 vezes mais energia do que aquela consumida em seu processo de produção, em geral de origem fóssil. O balanço energético do etanol obtido a partir do milho é de apenas 1,4 unidade, enquanto os combustíveis fósseis consomem 20\% mais energia do que o volume que disponibilizam durante seu uso.

\subsection{MEDIDAS PROTECIONISTAS, LEGISLAÇÃO ESPECÍFICA E CERTIFICAÇÕES}

Há um forte vínculo, nem sempre amistoso, entre os biocombustíveis e o petróleo. Para cada salto que o preço do petróleo dá nos mercados internacionais, como nos primeiro e segundo choque do petróleo na década de 70 e em 2008, não apenas incentiva prospecções de óleo em áreas antes descartadas (como pré-sal), como ainda estimula pesquisas e a utilização de fontes renováveis de energia. Por sua vez, a queda das cotações internacionais do petróleo tem o dom de parar pesquisas e programas relacionados aos biocombustíveis (REZENDE, 2008).

O petróleo, principal insumo da matriz energética mundial, manteve-se acima dos US $\$$ 100 em fevereiro de 2008 na esteira da crise financeira mundial, voltando para este patamar no começo de 2011. Soma-se a isto o esgotamento das suas reservas que estão concentradas em países de geopolítica complicada, causando ainda forte impacto nas emissões de gases que contribuem para o aumento do aquecimento global. Logo, os biocombustíveis estão sendo vistos como uma alternativa para substituir os derivados de petróleo uma vez que representam uma transição fácil e possível, que não exige mudança na infraestrutura de distribuição e armazenamento.

Neste contexto, o etanol brasileiro, proveniente da cana e que utiliza a queima de bagaço para produzir energia elétrica, tem se mostrado o combustível mais competitivo com a gasolina. Conforme as informações da Consultoria Datagro (REZENDE, 2008), o produto nacional custa US\$1,30 o galão, enquanto a gasolina está a US\$2,50 o galão.

Apesar de chamar a atenção e interesse por parte de vários países, o etanol apresenta alguns aspectos que não evoluíram: (i) faltam regulamentações nacionais que permitam o aumento da mistura de etanol na gasolina; (ii) os países produtores de cana encontram dificuldades para avançar a produção de etanol; (iii) faltam medidas para a liberação do mercado mundial de etanol, diante das limitações impostas por nações como EUA e UE; e (iv) falta definir um padrão internacional de etanol combustível, que ainda encontra-se em fase de discussão entre Brasil, EUA e UE.

Com relação aos subsídios concedidos aos biocombustíveis pelos países ricos, na ordem de US\$13 bilhões ao ano, não faltam críticas de entidades internacionais, como a Food and Agriculture Administration (FAO), e de países produtores como o Brasil, sob o argumento que 
a adoção de subsídios não estimula a concorrência. No entanto alguns países que adotam esta prática já estão programando cortes, como a França (REZENDE, 2008).

O protecionismo também se mostra na dificuldade de acesso aos mercados internacionais: os EUA adotam tarifa de US\$ 0,54 por galão de etanol importado fora da Carribean Basin Iniciative, mais taxa de 2,5\%, o que dificulta muito as importações diretas do Brasil. A UE, por sua vez, conta com imposto de importação de 0,192 euro por litro.

Ainda com relação a UE, tudo indica que pretende pisar no freio dos biocombustíveis, considerando que a Comissão de Indústria e Energia do Parlamento Europeu aprovou, em setembro de 2008 , projeto de lei que reduz a meta de consumo de $20 \%$ para $10 \%$ até 2020 . Entretanto, ainda é cedo para afirmar que a Europa vai encolher o seu programa de biocombustíveis, uma vez que a situação não está muito clara e se encontra em fase de intensas discussões.

Além do Brasil existem muitos projetos de biocombustíveis em andamento, em especial nos EUA. Esse país têm apresentado os maiores progressos nos últimos anos, suplantando o Brasil como maior produtor mundial de etanol, com a ajuda de investimentos públicos e privados. Aprovaram recentemente a lei de energia e estabeleceram a meta ambiciosa de substituir $20 \%$ da gasolina por biocombustíveis na década de 2020, não menos do que 136 bilhões de litros consumidos em 2022, além de investir em pesquisa de etanol de celulose.

Por fim, quando o assunto é biocombustíveis a questão principal reside na segurança de abastecimento, pois perguntas como "até quando haverá oferta de petróleo em grandes quantidades? A que valor? Das mãos de quem?” não param de ser feitas. Neste contexto, os biocombustíveis representam uma decisão estratégica e se apresentam como uma alternativa face a escassez de combustíveis que atingirá a próxima geração.

\subsection{ETANOL COMO COMMODITY}

EUA e Brasil, maiores produtores de etanol que respondem por cerca de $90 \%$ da oferta global, trabalham juntos para que o combustível ganhe mais espaço no mercado internacional. Embora sejam os maiores players mundiais deste produto, hoje atuam em lados opostos conforme ilustrado na Figura 1.

Segundo Scaramuzzo (2008) o etanol detém condições de se tornar uma commodity internacional, tendo em vista ser competitivo, mesmo com o recuo dos preços do petróleo. No entanto, o combustível enfrenta algumas barreiras que impedem uma penetração maior do produto no mercado mundial. 
FIGURA 1 - VISÕES DISTINTAS DO ETANOL ORIUNDO DO BRASIL E EUA
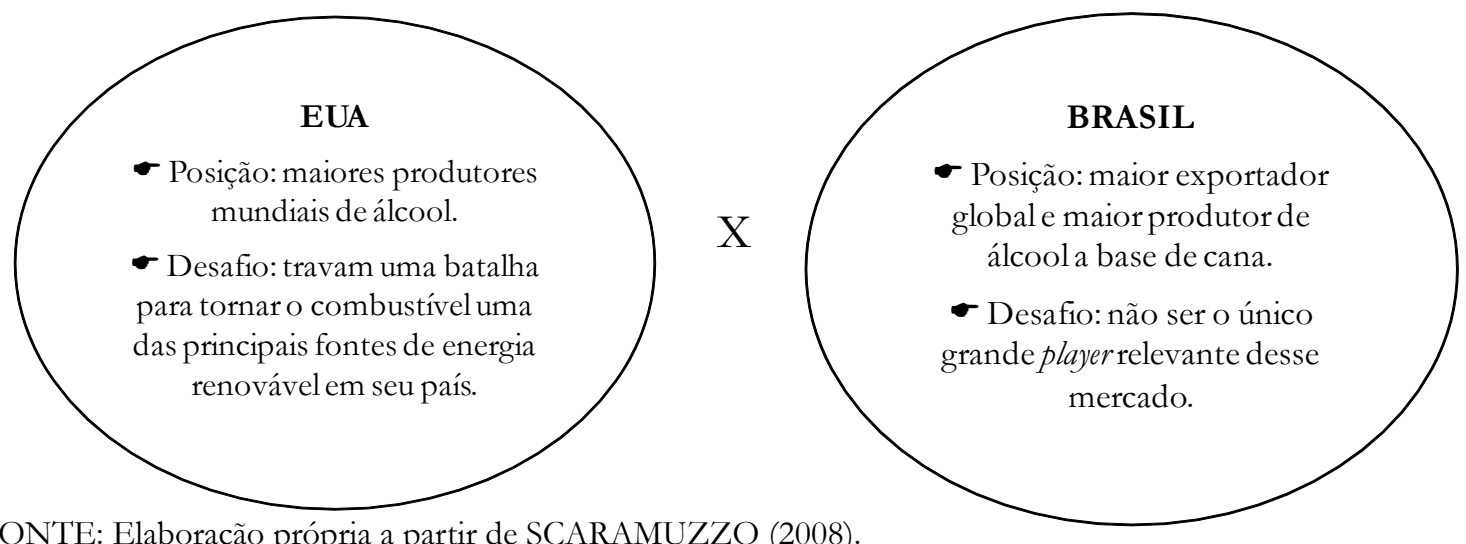

FONTE: Elaboração própria a partir de SCARAMUZZO (2008).

O primeiro passo necessário para que o etanol se torne uma commodity é que o produto tenha uma padronização internacional, com especificações bem definidas. Reuniões para alcançar este objetivo começaram a ser feitas no âmbito do Fórum Internacional dos Biocombustíveis com a participação de Brasil, EUA e UE; entretanto, tais países só chegaram a um acordo parcial nas especificações da padronização do álcool. Outros países foram convidados a participar das discussões, como Índia, China e África do Sul, mas não houve consenso. Com isto, as reuniões sobre o tema foram adiadas.

Além disso, é de grande importância que seja formado um grupo de países produtores e de consumidores para se construir o mercado internacional de álcool. O Brasil não pode ser o único produtor capaz de atender e abastecer outros mercados, já que os EUA são grandes produtores, mas não exportam. Outro fator que prejudica o Brasil é o acesso a mercados, uma vez que há protecionismo por parte dos potenciais importadores. Há discussões no Congresso americano para a retirada das tarifas impostas sobre o etanol brasileiro, mas ainda não existe sinalização para quando isso poderá acontecer.

Entretanto, Brasil e EUA têm unido forças para desenvolver o mercado de etanol em países da América Latina. A meta é criar demanda e fomentar países a produzirem o biocombustível para abastecer os futuros mercados consumidores.

\section{CONCLUSÃO}

O artigo propôs uma discussão de aspectos relevantes que devem ser observados para estimular o mercado nacional e internacional do bioetanol obtido a partir da cana-de-açúcar. O objetivo não é esgotar a discussão de tais questões, mas ampliar o debate e subsidiar os tomadores de decisão nacionais na construção de um cenário de desenvolvimento do setor de modo a consolidar a posição brasileira no mercado de biocombustíveis. 
Como visto no presente trabalho o agronegócio brasileiro é de grande importância para a economia nacional; sendo assim, a discussão de temas ligados a ele é necessária visando a sua dinamização e fortalecimento no âmbito de um desenvolvimento sustentável. O Brasil tem mostrado grande crescimento, apesar da crise mundial que se arrasta desde o final da década passada, e o setor agroindustrial da cana contribui sobremaneira para este desenvolvimento, pois gera empregos no campo, promove uma melhor distribuição de renda, é ambientalmente amigável e pode arrecadar investimentos no mercado de carbono.

O Brasil precisa aproveitar todo o conhecimento acumulado na produção de biocombustíveis e procurar nas próximas décadas passar de uma economia de exportação de matéria-prima para uma economia de produtos de alto valor agregado, contribuindo assim para o desenvolvimento da bioeconomia e aproveitando esta janela de oportunidade de aumentar seu crescimento econômico de modo sustentável.

\section{REFERÊNCIAS}

ABIODIESEL. Clipping de notícias. Disponível em: < http://www.abiodiesel.org.br/news/index. php?noticia $=7495>$. Acesso em: 07/2007.

BANCO NACIONAL DE DESENVOLVIMENTO (BNDES). Bioetanol de cana-de-açúcar: energia para o desenvolvimento sustentável. Organização BNDES e CGEE. Rio de Janeiro: BNDES, 2008. p. 316.

BASTOS, V.D. Etanol, Alcooquímica e Biorrefinarias. BNDES Setorial, Rio de Janeiro, n. 25, p. 5-38, mar. 2007.

CASTRO, G. Sem nenhum problema de espaço, avanços na agroenergia. Valor Especial Biocombustíveis. nov. 2008.

CORTEZ, L.A.B. Bioetanol de cana-de-açúcar: P\&D para produtividade e sustentabilidade. São Paulo: Blucher, 2010.

EMBAR. Disponível em:<http://www.embar.pt/conteudos/File/Noticias/ 2008/076\%20Bio combustveis \%20agravam\%20aquecim....pdf>. Acesso em: 08/2008.

INSTITUTO NACIONAL DE PESQUISAS ESPACIAIS. Notícias INPE. Disponível em: < http://www.inpe.br/noticias/noticia.php?Cod_Noticia=2023 > . Acesso em 01/2011.

MACEDO, I. C. et al. Greenhouse gases emissions in the production and use of ethanol from sugarcane in Brazil: The 2005/2006 averages and a prediction for 2020. Biomass and Bioenergy, v. 32, 2008.

MARTINES-FILHO, J.; BURNQUIST, B. L.; VIAN, C. E. F. Bioenergy and the rise of sugarcane-based ethanol in Brazil. Disponível em: <www.choicesmagazine.org>.

MINISTERIO DA AGRICULTURA, PECUARIA E ABASTECIMENTO (MAPA). Clipping do MAPA. Disponível em: < http://www.agricultura.gov.br>. Acesso em: 26/12/2010. 
MINISTERIO DO PLANEJAMENTO. Clipping do Ministério de Planejamento, Orçamento e Gestão. Disponível em: <http://clippingmp.planejamento.gov.br/cadastros/noticias/2011/1/13/cinco-commodities-garantem-43-da-exportacao-do-brasil>. Acesso em $01 / 2011$.

REZENDE, E. C. Ainda há muitas limitações no mercado internacional. Valor Especial Biocombustíveis, 2008.

SCARAMUZZO, M. Longo caminho para tornar o etanol em commodity. Valor Especial Biocombustíveis, 2008.

SECOM. Clipping de notícias. Disponível em: <http://www.secom.unb.br/bcopauta/ agricultura5.htm>. Acesso em: 08/2008.

SEIBEL, F. Combustível x Alimento. Revista Exame, n. 8, p. 104-109, mai. 2007.

UNICA - União da Indústria de Cana-de-Açúcar, 2009. Disponível em: $<$ http://www.unica. com.br>. Acesso em: 04/2009.

VEIGA FILHO, L. A estratégica brasileira em defesa do etanol de cana. Valor Especial Biocombustíveis, 2008. 